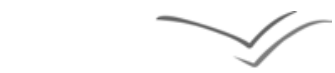

VERSITA

DOI 10.2478/jped-2013-0010

JoP 4 (2): $188-207$

\title{
Scottish and Slovak university student discussions about stigmatized persons: A challenge for education - moving towards democracy and inclusion
}

\section{Jana Plichtová}

Abstract: The paper compares discussions in 12 groups of university students $(6$ Slovak and 6 Scottish) equal in sex and age. The participants discussed the same problem - how to control the spread of HIV/AIDS and respect medical confidentiality (MC). Systematic comparisons revealed striking differences between the two national groups. The Scottish discussants were more cooperative than the Slovaks; they devoted more attention to analysing the problem and to creating a shared understanding of it. Although there was a temptation to contravene MC and the individual rights of those infected with HIV in both the Slovak and Scottish groups, only the Scottish discussants came to the conclusion, collaboratively and through argumentative exchange, that such proposals would be counterproductive in controlling the spread of HIV or in protecting public health. In the Slovak groups even participants who were opposed to discriminative proposals were not able to convince their fellow discussants that MC should not be contravened. Links are drawn between the findings and critical pedagogy and inclusion.

Key words: critical pedagogy and pedagogy of inclusion, small discussion groups, argumentational thinking, stigmatization, HIV/AIDS, medical confidentiality 
Morality, without justice, produces injustice, hence immorality. R. A. Cohen (1998, p.xvi)

\section{Introduction}

As Hume (1777) pointed out we are capable of feeling sympathy for those who are close to us. If the essence of any morality and justice is empathy and mutual respect and care, how can we overcome our limits of empathy toward the OTHER? Is rationality in the form of argumentative discussion an appropriate and sufficient means of agreeing on morals?

Critical sociology holds that social orders are not natural but are a consequence of classifying individuals, and that involves including and excluding people. Any such "operation of inclusion/exclusion is an act of violence perpetrated upon the world, and requires the support of a certain amount of coercion" (Baumann, 1993). Modernity itself is an open and contradictory project that tends to reduce all "Otherness" to "Sameness" by violence if necessary (Levinas, 1961/1995).

Numerous empirical studies indicate that in spite of deliberate initiatives and policies in liberal societies, individuals who are different, for instance, mentally or physically ill are deprived of being recognized as full human beings (see, for instance, Jodelet, 1984; Marková \& Farr, 1995; Joffe, 1998). For example, individuals with HIV are stigmatized, seen as being irresponsible, immoral and dirty individuals who do not deserve our sympathy and help. They are systematically disadvantaged in a variety of ways, including income, education, housing status, medical treatment and health (Link \& Phelan, 2001). As empirical research suggests, HIV stigma is considered to be a major barrier to accessing prevention, care and treatment (Chesney $\&$ Smith, 1999) and prevents uptake of HIV testing.

Nonetheless, one of the pillars of modernity is the political project of democracy and human rights. Thus Dewey $(1916 / 1961)$ argues that otherness and difference enrich the life of a pluralistic democracy and must be recognized. Without joint efforts and appropriate policies, individual freedom, a participatory way of living together and social growth are under threat. His assessment of the democratic quality of a given group, or community, is derived from two kind of observations: 1 . How numerous and varied are the interests which are consciously shared? 2. How full and free is interplay with other forms of associations? Such questions must be asked in relation to the education system as well. Does a particular educational system secure the plural and wide participation of learners and educators? What measures have been introduced against uniformity and the dangers of anti-humanism and the isolationism of the privileged class? Does the educational system 
merely serve as a social medium, transmitting basic cultural skills, techniques, knowledge and moral virtues or does it cultivate values, capabilities and social skills for a participatory way of living together? Does it struggle to achieve as much equity as possible between advantaged and disadvantaged groups? Does every human being, independent of the quantity or range of his personal endowment, have the right to equal opportunity to develop whatever gifts he has? Are the educators willing to recognize the different experiences and background of learners and deal with them in a creative, responsive and constructive way? What should be done to make education truly democratic and humanistic?

The exclusion, separation and even segregation of various types of OTHER, namely economically and culturally disadvantaged groups, can be observed in all European countries, including those in Central Europe, where in spite of the relatively homogeneous populations in terms of culture and ethnicity, the disparity in education is more salient. Numerous EU programmes and projects have been developed and funded to deal with disparities in education. Several professional networks developing a pedagogy of inclusive education have been established. Hidden to varying degrees in the extensive and comprehensive work they do is the problem of how to deter a majority group away from the tendency to protect its own privileges (exclusivity) at the expense of the OTHER. How can the tendency towards a uniformity of thinking be reduced? How can we foster empathy toward the OTHER? How can we diminish the tendency towards a totalitarian pattern of thinking. A pedagogy of inclusion has to find methods of revealing and unmasking habitual ways of thinking that lead to exclusion and a lack of empathy towards categories of people who are perceived to be different from the norm. These methods should involve active learning through the various experiences of students from different backgrounds, through cultivating the genuine constructive capacity of the students as well as deconstructive ideas and thoughts. It requires educators to adopt a different approach and they may require skills to facilitate deliberative communication among students, amongst other things. This paper reflects on my experiences as a researcher and educator in my attempts to cultivate deconstructive (critical) thinking in university students through the method of inquiry in how to solve current social problems.

\section{Method}

The data was collected as part of an international research project entitled Responsibilities and entitlements: a study in language and social repre- 
sentations in Central and Western Europe and subsequent local projects ${ }^{1}$. Six different topics were discussed in small groups (4-5 participants) and one of the most interesting topics, which produced quite different results between the two sets of language users, was medical confidentiality and HIV patient responsibilities. Discussions were held in small groups of 4-5 people $(\mathrm{N}=16)$ at the university during seminars or free periods. The participants (18-23 years old) were university students living in the Slovak capital of Bratislava or near Stirling in Scotland. The groups were homogeneous in terms of age and education. The groups were single-sex with equal numbers of male and female groups. The discussions were between 45 and 90 minutes long.

The participants were welcomed and familiarised with the basic rules of discussion and the goals of the research project. Once it was explained why the researcher would need to video the whole discussion and obtained the students' permission, the following problem was presented them:

\begin{abstract}
"You are Chief Medical Advisors at the Ministry of Health. Your primary task at present is to contain the spread of HIV/AIDS. People with HIV and AIDS are protected by medical confidentiality. This means that the doctor must not tell either his/her professional colleagues or the patient's spouse or anybody else that the patient has HIV. However, if the patient does not behave responsibly he or she can infect other people. As a group of advisors, you are responsible for the health of the public. What advice would you give to the Minister in resolving this dilemma?"
\end{abstract}

This kind of inquiry provides students with an opportunity to do something: to search for the facts that constitute the terms of the problem, listen to each other and deal with various points of view and the different experiences their peers have had. Such indeterminate problem with no a priori determined solution has important consequences for teaching - it produces genuine communication, reflective thinking and unleashes the creative potentialities of students.

\title{
The Analysis
}

The analysis was grounded in the pragmatic-dialogical theory of argumentation (van Eemeren \& Grootendorst, 1983) and in critical discourse

\footnotetext{
1 The leader of the research group was Professor I. Marková, 1997-1999. Later research
} on the rights and responsibilities of the individual was led by J. Plichtová. 
analysis (Reisigl \&Wodak, 2001; Wodak et al., 2009). It focused predominantly on exploring the use of referential and nominated strategies - (the way in which they are constructed linguistically and are representative of the identities of the social actors, the ways in which individual social actors are referred to, the ways in which they are "labelled"), predicative strategies characteristics attributed to those with HIV, judgements on their intentions and responsibility, argumentation strategies (how they justify the solutions proposed), expressed and unexpressed perspectives, premises and jointly accepted propositions.

Grootendorst and van Eemeren (2004), who consider discussion to be a means of resolving differences in opinion, suggest that the roles of the protagonist and antagonist are distinct - the protagonist presents his/her proposition and the antagonist criticises that proposition. If the proposition does not stand up to criticism, then the protagonist should recognise that the standpoint is not reasonable. If the proposition does stand up to criticism, then the antagonist should recognise that the protagonist's standpoint is reasonable. The assumption is that the participants come to a mutual agreement on the basis of argumentative discussion; however, this is the case only when the participants respect the rules of rational discussion (Van Eemeren, 1993). This means that all the discussants adhere to the agreed rules and do not seek to impose their opinions despite there being differences in opinion. If the discussants do not respect each other and if they are not willing to be attentive to one another and coordinate what they say, then they cannot reach an agreement that is acceptable to all. However, the pragma-dialectical model for discussion does not explicitly refer to the societal, moral, subjective and intersubjective dimension of each social and societal problem. If we wish to resolve any kind of social issue, then we need to understand the various interdependencies between the material and the rational side (the objective dimension) and the subjective side ("seeing" the problem from the perspective of different actors), and the societal side (morals, political values, ideological beliefs, institutional settings, legal system). In analysing how the discussion develops I shall therefore pay attention how the discussants reflect on and consider the subjectivity of the various actors, the connections between the material, social, ideological, moral and subjective dimension of the societal problems that are revealed. By subjectivity we mean the ability to reflect on the positions of others and to understand the subjectivity of the other person. Intersubjectivity means the outcome of a (critical, open) dialogue which leads to a change in the original subjectivity, expanding it. The discussion therefore does not simply involve rationality, but also the processes by which we understand others through empathy. 


\section{The Scottish Discussion}

F- facilitator, A, B, C, D - participants (abbreviated)

Clarifying the problem and confrontation stage

B: Clarifies the problem:

"It may not be how we control the spread of HIV is basically our main concern. Ideally we want to keep the confidentiality as well... How are we going to control the spread of HIV while keeping the confidentiality of the patient?"

D: Continues clarifying and asks all the participants the following question:

"You're assuming that people with HIV aren't going to act responsibly and avoid blood contact with other people or whatever? Maybe they are."

The question includes knowledge of the fact that HIV is transmittable only via blood and that it is not simply about sexual contact. Thus, so long as no injury occurs, there is no blood contamination (objective dimension of spread of HIV). The discussant reflects upon the fact that those who are HIV positive do not necessarily behave irresponsibly.

C: Suggests a different interpretation of the task:

"The question we are really discussing is should we change the rules of confidentiality in the case of people who have got HIV."

B: Objects and repeats that it is not about controlling the spread of HIV but about maintaining medical confidentiality (MC).

C: Insists on a particular interpretation of the problem: (the role of antagonist and protagonist are mixed).

"I do agree, it seems to be the question of is there some sort of precedent for relaxing confidentiality laws in the case of HIV because of people with HIV behaving irresponsibly."

B: Disagrees and argues on the basis of the oaths and binding laws to which the medical profession have agreed: 
"This is the issue, isn't it, do you then change the oaths and the binding laws to which they have signed themselves"

A: Refers to C's idea and asks whether exceptions to MC where HIV is concerned would give doctors a free hand in dealing with irresponsible HIV sufferers and 2. whether the spread of HIV could be reduced through monitoring those who are HIV.

B: Disagrees with A and argues on the basis of the law that guarantees MC.

A: Rejects this arguing that it is simply a law and that it can be changed at any time.

D: Argues on the basis of analogy with the law on child abuse, where the law on confidentiality does not apply.

A: Rejects the idea that an appropriate analogy can be drawn with child abuse - where child abuse is concerned there is no doubt as to who the victim is and who the perpetrator is, whereas in those who are HIV infected the victim is also the perpetrator. Dividing HIV positive people up into victims and perpetrators is unacceptable and impossible in practice since by definition a person who has just been infected is a victim and at the same time is a potential perpetrator. The participant casts doubt on there being any reason why one patient should retain anonymity and another not. 'A' argues that using terms such as guilt, innocence, perpetrator and victim is not constructive. Abolishing MC where HIV is concerned would not prevent it from spreading. (Here are the links between the medical and ethical aspects of problem and the moral obligation to protect all patients equally clarified).

$\mathrm{D}$ and B: Develop their argumentation further: abolishing medical confidentiality where HIV is concerned would be counterproductive, since people would worry about becoming stigmatised and would not go for tests.

These arguments relate to the subjective dimension of the problem (fear, worries people have about HIV) and the social dimension of the problem (stigma), since society sees those infected with HIV as socially deviant. 
C: Points out that the rules are binding for all and highlights the difficulties that might arise should exceptions be made (slippery slope argument):

"You've obviously got a wider issue here haven't you, because if you relax it for one category of disease then you could say should it be relaxed for other diseases which are also contagious?"

A: Agrees and justifies this by rejecting solutions that are based on searching for a culprit.

"Blaming is not helpful. If we accuse someone of spreading an infectious disease, then we are not solving the problem. If the rights of one group of people with a particular disease were curtailed in relation to the rights of others, then that would indeed mean deciding who the culprit is. Curtailing the rights of those infected with HIV would lead to unacceptable inequalities in the way they are treated."

Participant A's argument is based on the principle that unequal treatment is unacceptable. The conclusion from all this is that the only acceptable solution is to focus on educating the public.

The participants come to mutually recognise that $\mathrm{MC}$ offers protection to those who are infected with HIV. It protects their identity and protects them against stigmatisation. The participants then clarify the pragmatic dimension of subjectivity in the sense of knowledge and knowing: if those who are HIV positive discover in time that they are infected with HIV, then they will know that they should behave responsibly and protect their partners from infection.

\section{Revealed Interdependencies}

1. MC protects those who are infected with HIV from potential stigmatisation, thereby reducing their fears and encouraging them to willingly undergo voluntary testing.

2. The risk of HIV spreading is reduced by the fact that those infected will find out in time that they have HIV in their blood.

A: Begins a new topic - protecting the private sphere.

B: Gives an example of a pregnant woman who smokes. It is not possible in this case either to take the cigarette out of 
her mouth and justify the act by saying that it endangers the health of her child. Equally it is not possible to ban an HIV positive person from having sex or sharing needles (the argumentation is based on analogy). B further argues in normative terms (using a general principle) - “...it's the private sphere and no one has the right to regulate it through orders and bans."

\section{Recommendations to Ministry of Health}

1. Educate the public: a. reduce the stigma of HIV/AIDS, b. encourage people to undergo testing, c. oppose the belief that if you catch it then you are to blame (changing public opinion), d. explain what safe sex is.

2. Keep in place tools that encourage mutual trust and openness amongst people (for example, MC).

3. Motivate people with HIV to behave responsibly, provide them with detailed information on how to prevent others from becoming infected. This was also justified:

"The fact that they became infected probably means that they didn't take sufficient protective measures, perhaps because they weren't aware of them, so reminding them of them would help protect their potential partners."

4. Foster HOPE in those with HIV, encourage them to believe that sensible behaviour leads to positive results and increases their life expectancy.

"If someone who is infected with HIV feels that they been sentenced to death, with no opportunity to live their life, if they feel excluded from society, then it produces pathological changes in them - reckless behaviour and a desire for revenge." (subjective negativity could be turned around for the benefit of all of us).

\section{The Slovak Discussion}

Slovak discussants did not clarify the problem itself and went straight on recommendations. 
D: Suggests that a distinction should be made between "innocent" and "guilty" HIV sufferers, i.e. between those who became infected through their own actions and those who were "innocent", that is, infected through blood transfusions etc. By categorising individuals in this way, it is possible to predict that 1. the guilty will wish to hide the fact that they are infected, 2. that those who are innocent will voluntarily and publicly admit that they have the disease.

E: Accepts the proposed categorisation, but predicts different behaviour patterns. 1. Those who are guilty, who became infected as a consequence of their lifestyle, will not care whether anybody finds out or not, 2. those who are innocent will tend to hide their status. No justification is given for the categorisation and the predictions on behaviour.

A: Rejects the notion of categorising people as innocent and guilty. What is important is establishing whether the infected will spread HIV further or not.

D: Supports the idea of categorising those who are infected with HIV as innocent or guilty using an argumentation strategy: “... those who are guilty are irresponsible people who will spread the disease further and so it is essential to intervene" (a negative predictive framework and circular reasoning).

B: Suggests that doctors should be obliged to inform others about the patient's disease.

D: Agrees with B and backs up the idea using an argumentative scheme:

"Informing others about those who are HIV positive is the only effective form of prevention. Otherwise, more people will become infected."

The argumentative scheme presupposes dividing people up into "us" and "them", which is an antagonism between healthy and infected people, based on fear of the risks.

F: Asks whether maintaining MC in fact runs counter to protecting the public interest. 
B: Suggests that MC should be abolished where HIV infected people are concerned and justifies this using the following predictive strategy:

"Those infected with HIV are simply pursuing their own selfish goals (having fun and infecting others at the same time), and they have to be prevented from doing this."

Abolishing $\mathrm{MC}$ is therefore justified by attributing negative character traits (irresponsibility and immorality) to HIV sufferers. Hedonism and sexual promiscuity are seen as being the causes of the spread of infection (a lack of knowledge about the substance of the issue).

D: Agrees with the predictive strategy that those infected with HIV are immoral and so do not deserve to be protected by MC. $\mathrm{D}$ asks a rhetorical question: "How can we distinguish between responsible and irresponsible HIV sufferers?", and then supplies an answer.

"Since it is impossible to distinguish between those who are responsible and those who are not, MC should be abolished for all those infected with HIV."

This type of totalitarian fallacy ${ }^{2}$ - the need to sacrifice those who are not members of our group is rather frequent. The question of JUSTICE is neglected by Slovak participants because OUR interests should take priority (because WE are on the right track).

F: asks: "Is a doctor "entitled" to inform a third person about a patient's disease?"

D: Expresses the opinion that a doctor is indeed "entitled" to do so.

B: Disagrees with the idea of abolishing MC and then justifies his position since: 1 . there is a danger that the information

2 We should bear in mind that Dewey's first criterion for assessing the democratic quality of a given group (community and society) is an internal one. It concerns the plurality of "interests which are consciously shared" (1916, p. 89). A pluralistic and participatory way of life, where people with different interests live together stands in opposition to uniformity and the dangers of totalitarianism. However, a plural and participatory way of life requires an open-mindedness towards different interests and the "recognition of mutual interests" (ibid, p. 92). 
could be misused and 2. there is a danger of stigmatisation (the societal dimension of the problem).

A: Agrees and gives the example of the film Philadelphia.

D: Refuses to acknowledge the argumentation that has gone before. D objects saying that if an HIV sufferer does not inform his/her partner then the partner's life is in danger. This argumentation strategy exaggerates the risks of infection and prematurely shuts down the issue without any further exploration of the substance of the matter - that is, what are the dangers of sexual intercourse, what conditions are required for HIV to be transmitted and is it possible to protect oneself against HIV infection.

E: Repeats the argument that those with AIDS are stigmatised in society.

D: Uses E's argumentation in favour of D's argument and argues that stigmatising those infected with HIV is beneficial, since it warns the OTHERS off. D adds that "Those who are infected only have themselves to blame, since they chose that kind of lifestyle"

F: Wonders about those who have been infected through transfusion and are therefore "innocent" (objection against inconsistent arguments).

D: Accepts that this might have a negative impact on those who are "innocent" and that "a few people might have their lives destroyed". D insists, however, that it is an acceptable solution which will protect many human lives.

Non-consensual suggestions and common beliefs

Public interest is narrowed down to the healthy section of the population, which takes precedence where justice and equality are concerned in relation to the right to equal treatment. There is a false assumption that there are no other ways of protecting against HIV. The subjectivity of those with HIV is negativised at first. Their responsibility in regard to others is doubted and so the road to retaliation opens up: to exclusion and discrimination. This scheme creates the false appearance of JUSTICE. Its convincing force is 
grounded in the false predication about the essentially negative subjectivity of the OTHER and is associated with the devaluation/dehumanization of the personal and social identity of the OTHER - people with HIV).

F: Asks everyone whether they would agree with MC being abolished.

They state that they have not reached agreement.

$\mathrm{B}$ is not sure whether this is the real problem, D is for abolishing MC, since HIV infected people will continue to spread HIV further and go unpunished, A suggests that they should hold a referendum on the issue, $\mathrm{C}$ doubts that punishment would deter those who knew they were dying.

D: Once more adopts the role of protagonist and suggests that those who are infected should be monitored. D does note that this would be an infringement of personal liberty, but that it could be defended on the grounds that those infected present a danger to others (pathetic fallacy). If people are aware that they are HIV positive and behave irresponsibly to others, by not admitting to being infected, then D suggests that strict sanctions should be imposed - isolation and imprisonment.

A: Suggests that a list of those infected should be published in the newspapers (to control, to ostracise). This indicates a shared assumption of distrust in relation to the responsibilities those infected with HIV have towards US.

D: Adds the following "pragmatic" justification for publicising the identities of those infected with HIV: "... the infected could use the list as a way of meeting new people." The argumentative strategy - "well it's for their own benefit, we're not doing anything unethical" negates the subjectivity of those infected with HIV and thus justifies the chosen course of action.

The common understanding is that immorality (a promiscuous lifestyle) is the cause of HIV infection. WE have the "right" to act against the HIV infected, because there is no other way of protecting OURSELVES. 


\section{Comparison of Stages in the Scottish and Slovak Discussion}

In the opening stages the Scottish discussants mapped out the ideas they had in common and defined equality as equality of treatment. Shared notions of the principals of equality and protecting privacy were defined explicitly through repeated questions and mutual assurances as to whether the principles had been understood in the same way. The discussants collaboratively agreed on a respect the privacy, medical confidentiality, equality of treatment and acknowledged an individual responsibility and rationality. The discussants agreed that 1 . classification of people as guilty or innocent, as victims or perpetrators and treating them differently are all clear examples of stigmatisation, so these solutions are unacceptable, 2. MC cannot be abolished in the case of HIV sufferers, since that would lead to discrimination of this group of patients with all the negative social and psychological consequences which that would entail. The concluding stage of the discussion led to the discussants agreeing on what the participants thought were the duties and responsibilities of the government in creating conditions for equality for all, ensuring that the public has access to the relevant information, motivating people to behave responsibly in terms of their health, reducing fear of the disease through education and enlightenment, and openly reflecting upon all the important social implications of HIV/AIDS and thereby reducing the stigma attached to HIV / AIDS.

The confrontational stage in the Slovak discussion was based on the premise that those who are HIV positive should be categorised as innocent or guilty. The antagonist disagreed with this, but did not use a single principled argument (equal treatment, for instance). The protagonist dominated the group defending classification according to supposed immorality of HIV positive persons and not taking the differing opinions of the discussants into consideration. The protagonist was enough rhetorically skilled to defend his convictions by arguing that 1. public interest has to take precedence over the good of an individual who is a "threat" to society. 2. HIV is spread through the immoral lifestyle those infected lead. The discussants did not clarify the issue of whether protection of public health required that MC be maintained or not. No one successfully questioned the argumentative strategies used to defend stigmatisation of persons with HIV. 
Table 1

Contrasting set of common beliefs in the Scottish and Slovak discussions

\begin{tabular}{|l|l|l|}
\hline & Slovak moral discourse & Scottish moral discourse \\
\hline $\begin{array}{l}\text { The individuals } \\
\text { with HIV }\end{array}$ & $\begin{array}{l}\text { Their autonomous re- } \\
\text { sponsibility is not recog- } \\
\text { nized. They must be con- } \\
\text { trolled by the authorities. }\end{array}$ & $\begin{array}{l}\text { Their autonomous responsibility is } \\
\text { recognized (explicitly in relation to } \\
\text { oneself and one's partners = taking } \\
\text { precautions + having the informa- } \\
\text { tion and knowledge). }\end{array}$ \\
\hline The government & $\begin{array}{l}\text { The state has to control } \\
\text { and punish the individu- } \\
\text { als with HIV. }\end{array}$ & $\begin{array}{l}\text { The state has to protect the autono- } \\
\text { my of any individual. MC and equal } \\
\text { medical treatment should be guar- } \\
\text { anteed. }\end{array}$ \\
\hline
\end{tabular}

\section{Comparison of the Nominal and Predicative Strategies in the Slovak and Scottish Discussions}

There was a contrast between the Slovak groups, which labelled people with HIV as "ill, infected, HIV positive, AIDS-carrier, gay, homosexual, junkie and emphasised their "unclean" and "immoral lifestyles", and the Scottish group which used more neutral labels, such as "someone who is HIV positive" and "a person who has AIDS". The Scottish discussants did not judge people with HIV in terms of the personality traits that the Slovak discussants frequently referred to: immorality, frivolousness, mental instability, promiscuity, asocial, vindictiveness and so on. If any of the discussants described those infected with HIV in negative terms, a dissenter would always emerge and mitigate the generalisation, doubting or refuting the statement. This never occurred in the Slovak group. When one of the Scottish discussants used a polarising argumentative scheme ("we healthy people" versus "the sick"), there was always an antagonist to explicitly cast doubt on the statement.

\section{Summary}

Since the discussants in both the language groups displayed a tendency to separate those with HIV (the Other) from OURSELVES, to attribute negative characteristics to them and discriminate against them (Link $\&$ Phelan, 2001), it would seem that the stigma associated with people with HIV exists in both societies (Scottish and Slovak) due to perceived antagonistic interests. Nevertheless in the later phase of discussions, great differences were found between the two groups of language users as described above. In the final stage of discussion, Scottish students considered the interdependence between the societal, interpersonal and personal dimensions of 
the problem and suggested a solution that would improve public health without sacrificing the rights of persons with HIV and destroying trust in the medical profession. The fact that the Scottish solution was much more inclusive than the Slovak one is an important finding because it indicates that the nature of education and public discourse matter. In British society the tendency to exclude and to discriminate against the OTHER (in this case the HIV infected) has been challenged by an opposing discourse grounded in a belief in individual rationality and autonomous responsibility. By contrast in Slovak society the stigma of HIV is bolstered by a widespread and generalized distrust of individual moral autonomy and doubts about the individual's capacity to control his/her own emotions and desires. It should be explained that the authorities in the Catholic Church in Slovakia perceive HIV as being a punishment for an immoral lifestyle and use fear of HIV as a means of disciplining the sexual behaviour of their congregation.

While the Scottish discussants reproduce convincing arguments for not discriminating against people with HIV, the Slovak discussants utilize various argumentative strategies to "justify" the punishment of and discrimination against persons with HIV. This difference was validated across all 24 groups and later on through the use of social dilemmas in my own teaching.

The Scottish discussants explored and understood appropriately the interdependency between the societal dimension of the problem (stigmatisation), legal and institutional settings and the responsibility of persons with HIV. They comprehended that having medical knowledge about HIV transmission is an important factor in increasing the number of people taking protective measures against HIV and that the threat of discrimination reduces the willingness of persons with HIV to reveal their status to their partners. Willingness to undergo HIV testing is dependent on medical confidentiality being maintained and having trust in the medical profession. By contrast none of these interdependencies between the subjective and societal dimensions of the problem were revealed by the Slovak discussants, apart from the link between the stigma of HIV and willingness to undergo HIV testing.

In addition, the comparison of the pattern of communication within the Scottish and Slovak groups of students revealed that the Slovaks were ill prepared to participate in argumentational discussion. They had not had enough experience of how to analyse the problem nor how to distinguish the various aspects of the problem. They were not ready to intellectualize the problem nor use the appropriate concepts and knowledge. They were made captive by fear and were constrained by the narrow meaning of morals. It indicates that the Slovak educational system is much less capable than the Scottish one of stimulating critical, constructive and deconstructive thinking. The Slovak university students have rarely, if ever, had the opportunity 
to practice argumentative discussion or to participate in collaborative dialogue. Similarly, Zápotočná and Lukšik (2010) found that in (Slovak) schools there are very few opportunities for pupils to take part in discussions where freedom of speech and the required skills, such as expressing and formulating opinions, arguing and understanding different opinions, could be developed. This deficit in the skills, virtues, rules and practices of democratic communication has been documented by previous research as well (see, for instance, Plichtová \& Moodie, 1998; Moodie et al., 1995; Plichtová \&Berecká, 1998, 1999; Berecká, 1998).

\section{Interpretation}

From a critical psychology perspective, the discussions could be considered as texts and societal background, as textuality (education system, public discourse, power structure, shared symbols, meanings, and so on). The Slovak textuality is permeated with symbols of punishment and violence against the OTHER, by acts of dehumanisation, punishment and exclusion. By contrast, the Scottish textuality is more inclusive. Its shared meanings are anchored in the concepts of human rights, individual freedom, autonomous responsibility and mutual interdependency. In other words, the reasoning that the students are actually capable of producing depends not only on the knowledge stock and experience they have already obtained, but also on the culture and state of intellectual inquiry within that culture, especially the degree to which what is already known is public and communicable.

Dewey's distinction (1891/1967) between habits and routines provides us with another means by which to conceptualize the relationship between the discussions and the societal and social contexts, but this time from a dynamic and communication perspective. According to Dewey, habits are powers the individual has acquired through social communication (exchange and transaction), while customs are collective habits that always precede individual acquisition. Customs are part of culture - they create the comprehensive context through which our experiences take place. This means that our students' discussions habitually reproduced things that had been transmitted to them via the family, school, Church, and so on. This suggests that our educational system fails to use the transformative and emancipatory potential of education and inclusive pedagogy. Instead of nurturing intellectual quality, connectedness, recognition of difference, and emotional responsibility (Gabel, 2002), our educational institutions transmit a narrow conception of morality, negative emotions towards the OTHER, close-minded thinking and feelings. 
What is to be done? Our system of education should be radically changed so that teaching becomes democratic, socially responsible, inclusive, communicative and critical. Reforms should go hand in hand with the dialogical engagement of educators with learners. They should engage all their students in constructive activity and facilitate development of reflective, constructive and critical and open-minded thinking. They should explore the appropriate cultural tools and resources to deconstruct old habits and meanings and to reconstruct them in the interests of freedom, dignity and the equality of human beings. The subjectivity and diversity of students' standpoints and their original perspectives should be considered essential conditions for growth. If learners were just copies of their environment, nothing new could ever emerge.

One of the methods in which learners' reasoning capacities can be developed is through argumentative discussion among themselves and another is open dialogue between educators and learners. Both methods may lead them to tentative deconstruction of the habitual and customary perspectives that have held them captive in the morality of the nineteenth century. Critical social psychology can provide a means of facilitating various types of social communication in order to reveal and unmask habitual ways of thinking and nurture empathy towards categories of people who are perceived as different. Performing drama, conducting role plays, simulating trials, conducting interviews, writing and reading autobiographies, deconstructing myths and symbols are all suitable methods of restoring recognition of all human beings.

University students should have more opportunities to exercise the skills necessary for participating in open discussions. Their capacities to reason should be challenged by constructive and creative tasks, such as comparing normative and scientific theories and making judgements about the viabilities of these theories in a societal context, and discovering the validity and consistency of their arguments. It is the social intelligence of the learners that will in the end decide whether we succeed in living together in freedom without violence and coercion.

\section{References}

Berecká, O. (1998). Diskurziune charakteristiky demokracie v malých skupinách [Discursive characteristics of democracy in small groups], unpublished dissertation. Bratislava: Department of Social and Biological Communication, Slovak Academy of Sciences.

Bauman, Z. (1993). Postmodern ethics. Oxford: Basil Blackwell.

Chesny, M., \& Smith, A. (1999). Critical delays in testing and care: The potential role of stigma. American Behavior Scientist, 42, 1162-1174.

Cohen, R. A. (1998). Foreword to E. Levinas: Otherwise than being or beyond essence. Pittsburg: Duquesne University Press. 
Dewey, J. (1916/1961). Democracy and education. New York : The Macmillan Company.

Dewey, J. (1891/1967). Psychology. In: The early works of John Dewey, vol. 2. Carbondale and Edwardsville: Southern Illinois University Press.

Gabel, S. (2002). Some conceptual problems with critical pedagogy. Curriculum Inquiry, 32 (2), 177-201.

Grootendorst, R., \& Van Eemeren, F. H. (2004). A systematic theory of argumentation: The pragma-dialectical approach. Cambridge: Cambridge Press.

Jodelet, D. (1989/1991). Madness and social representation [Original title: Folies et Représentations Sociales T. Pownall). New York: Harvester Wheatsheaf.

Levinas, E. (1961/1995). Totality and infinity. Pittsburg, PA: Duquesne University Press.

Link, B.G., \& Phelan, J. C. (2001). Conceptualizing stigma. Annual Review of Sociology, 27, 363-385.

Link, B.G., \& Phelan, J. C. (2006). Stigma and it public health implication. Lancet, 667-529.

Mahajana, A.P., Saylesc, J. N., Patela, V. A., Remiend, R. H., Sawiresa, S. R., Daniel J. Ortize, D. J., Szekeresa G., \& Coatesa, T. J. (2008). Stigma in the HIV/AIDS epidemic: a review of the literature and recommendations for the way forward. AIDS, 22 (suppl 2): 67-S79

Marková, I., \& Farr, R. (Eds.) (1995). Representations of health, illness and handicap. Amsterdam: Harwood Academic.

Moodie, E., Marková, I., \& Plichtová, J.(1995). Lay Representations of Democracy: A Study in Two Cultures. Culture and Psychology, 1, 423-453.

Plichtová J., \& Berecká, O. (1998). Diskusná skupina - "miniatúra mysliacej spoločnosti" [Discussion groups - "a thinking society in miniature"]. Človek a spoločnost" (Internet journal for theory and research in social sciences), 1, 3.

Plichtová, J., \& Berecká, O. (1999). Postoje v argumentativnom kontexte [Attitudes in arguments]. In: V. Bačová (Ed.), Súčasnost’ a perspektívy psychológie. Košice: FF PU, Katedra psychológie.

Plichtová, J., \& Moodie, E. (1998). Proposals, justifications and beliefs in discussion groups: Slovak - Scottish comparison. Paris, 18 - 21 May, European Laboratory of Social Psychology: Maison des Sciences de l'Homme.

Reisigl, M., \& Wodak, R. (2001). Discourse and discrimination: Rhetorics of racism and antisemitism. London: Routledge

Van Eemeren, F. H. (1993). Reconstructing argumentative discourse. Tuscaloosa, Alabama: The University of Alabama Press.

Van Eemeren, F. H., \& Grootendorst, R. (1992). Argumentation, communication and fallacies: A pragma-dialectical perspective. Hillsdale, NJ: Lawrence Erlbaum.

Wodak, R., Cillia, R., Reisigl, M., \& Liebhart, K. (2009). The discoursive construction of national identity. $2^{\text {nd }}$ ed. Edinburgh: Edinburgh University Press.

Zápotočná, O., \& Lukšík, I. (2010). Modely občianskeho vzdelávania a ich podiel na formovaní aktívneho demokratického občianstva [Models of civic education and how they contribute to the formation of an active, democratic citizenship]. In J. Plichtová (Ed.), Občianstvo, participácia a deliberácia na Slovensku: teória a realita (pp. 313-332). Bratislava: Veda. 


\section{Author:}

Jana Plichtová, CSc., Professor

Institute for Research in Social Communication, Slovak Academy of Sciences

Dúbravská cesta 9

84104 Bratislava 4

Slovakia

email: jana.plichtova@savba.sk 